\title{
Automation System and Monitoring in the Hydroponic Cultivation Process Integrated with Internet Network
}

\author{
Abdullah \\ Institut Teknologi Bisnis Indonesia \\ Medan, Indonesia \\ abdullah2187@gmail.com
}

\author{
Roberto Kaban \\ Institut Teknologi Bisnis Indonesia \\ Medan, Indonesia \\ roberto.kaban@yahoo.com
}

\begin{abstract}
The monitoring system in nutrient solution is something that must be considered in the process of hydroponic cultivation, because it is from this nutrient solution that ensures the result and quality of the hydroponic plant itself. Important variables such as acidity, temperature and concentration of nutrient solution are the values that determine whether or not the nutrient solution will be given to the hydroponic plant. Important variables in improper nutrient solutions will make the hydroponic cultivation process for crop failure. This research uses a PH sensor that serves to detect the acidity level of the nutrient solution and the DHT11 temperature sensor which functions to read the condition of the nutrient solution temperature and the TDS sensor detects the concentration of the nutrient solution. The microcontroller used is the type of Atmega328 which is used as a processing of all inputs and outputs. This monitoring system is connected to the internet so that all sensor reading values can be viewed through an Android phone and can be accessed via the Web, so that the monitoring process can be done remotely. From the test results obtained prove that this system has been successfully integrated and is able to work well according to the desired target, which can monitor the acidity and temperature conditions in hydroponic plants that can be accessed directly through mobile phones and has been integrated with the internet network.
\end{abstract}

Keywords - automation; monitoring; cultivation; hydroponics; internet

\section{INTRODUCTION}

Hydroponics is a process of planting in which the process of planting plants uses water as media without soil. Hydroponic cultivation can be a solution when land is limited so that the cultivation process no longer has to be carried out in villages that still have sufficient land, but urban communities can also do and develop the process. The hydroponic planting process can be carried out in a container that uses water or materials such as sand, broken tiles, gravel and others as a basis for plant growth as well as acting as a plant physiology process (Helmy, 2016). he water used is water that has been adjusted to the $\mathrm{pH}$ level, added with nutrients with a certain amount of Ppm that helps the process of plant growth.

There are several factors that greatly affect the success of the hydroponic cultivation process, namely the suitability of temperature, humidity, water quality ( $\mathrm{pH}$ of water) and the amount of Ppm of nutrients needed by hydroponic plants. If the important factors above are not handled or carried out properly and appropriately, then the hydroponic plants produced are of poor quality or the hydroponic plants fail to harvest (Garg, 2016).

The hydroponic farmers are currently working on the hydroponic cultivation process manually through parameter measurements that are carried out periodically and have an impact on the length of the process of adjusting conditions on the hydroponic plants plus a sudden change in environmental conditions. Then the chances of crop failure in hydroponic plants are quite large. For this reason, many farmers outsmart the problem by using the amount of human resources by always checking the condition of the plant regularly (Prakosa, 2019). Of course this is a big problem for farmers or hydroponic plant developers, because the process of the cultivation is very ineffective.

In this research, a prototype of an automation system and monitoring of hydroponic cultivation processes that have been integrated into the internet network can overcome the problem of farmers or developers of hydroponic plants. All 
settings and working of system is done automatically in one prototype, such as controlling an important parameter for hydroponic cultivation (temperature, soil moisture, measurement of $\mathrm{pH}$ levels and nutrition of $\mathrm{Ppm}$ values). So that the condition of these parameters continues to be maintained according to plant needs. This system can also automatically control the cultivation process, such as the provision of nutrition according to the needs of the hydroponic plant. moreover, this prototype is equipped with a monitoring application feature that has integrated an internet network that can be installed on the mobile phones of each hydroponic farmer, in this application will be displayed all the conditions of hydroponic plants along with its important parameters, in this application also has been equipped with a remote control that can control work process of cultivation. So that farmers and hydroponic developers can carry out the hydroponic cultivation process efficiently and can also produce good quality plants. Without having to be afraid of changes in environmental conditions, and farmers also do not have to intensely check the condition of their crops and are directly not dependent anymore with the use of many human resources.

\section{Literature REVIEW}

A. System

A system is a unit consisting of components or elements that are linked together to facilitate the flow of information in achieving a goal. The system used in this reasearch, namely the automation system and monitoring of the hydroponic cultivation process in improving the quality of the results of plants integrated with the internet network. In general, the concept of the system used in this reasearch consists of three main parts such as: The control system algorithm is an inseparable part of a system. The control system functions to combine / connect electronic hardware systems and mechanical designs properly so as to achieve a function as desired, so that the mechanical system, hardware and control system algorithm are inseparable parts in making a system (M.F.Saaid, 2015) (Kulkarni, 2017).

\section{B. Hydroponic}

Hydroponic plants are plants with planting media that do not use soil. In general, hydroponic plants use water as their growing media. The hydroponic cultivation process is a cultivation process that is friendly to the environment. The result of plants from the hydroponic cultivation process is healthier and safe for consumption (Joshi, 2018). Hydroponic cultivation technology has experienced very rapid development, which was originally all processed manually, with the development of this technology the process of hydroponic cultivation has been done automatically, both monitoring important variables and controlling of electronic devices used in the process of hydroponic cultivation. This technique of hydroponic cultivation process is widely applied on limited land and on land that is considered infertile (Sahin, 2014).

\section{Sensor}

To control automation system and monitoring of the hydroponic cultivation process in improving the quality of the crop integrated with internet network, then the system must be equipped with sensors that are intended as data information which will then be processed by the controller so that the system can perform its duties as desired (Wiedjaja, 2017) (mouser.com, DHT11-Technical-Data-Sheet , 2019) (sparkfun.com, PH Sensor datasheet, 2019) (media.digikey.com, TDS Sensor Datasheet, 2019). The sensor used is the temperature and humidity sensor of DHT11, PH sensor, TDS (Total Dissolve Solid) sensor as a detector for solution density. Sensor image is seen in the Figure below:

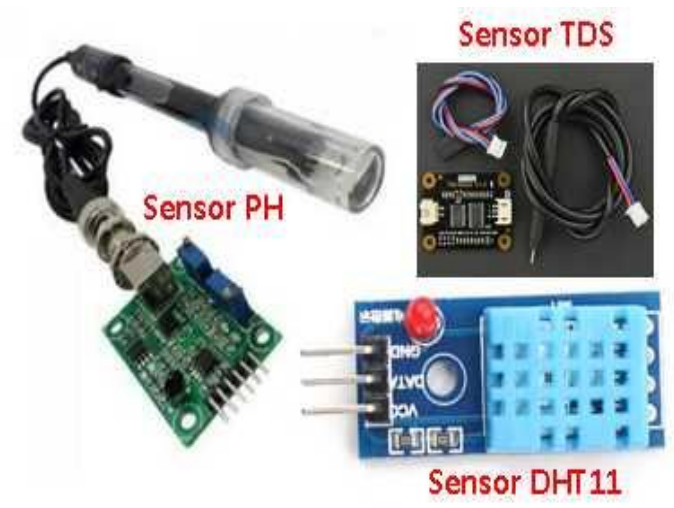

Figure1. Sensors used for the system

\section{Embedded Systems}

Embedded systems are computer-based systems that are programmed for specific tasks and are embedded as parts of a computer system or in a piece of equipment and sometimes do not show that the equipment is controlled by a computer. The processor or controller that is most widely used in embedded systems is a microcontroller, in the form of a chip. In this research, ESP32 is used, where ESP32 is already integrated into the ATmega328 microcontroller, Wifi modules and Bluetooth modules (sparkfun.com, Mikrokontroler AVR Atmega328 datasheet, 2019) (sparkfun.com, ESP32 datasheet, 2019). 

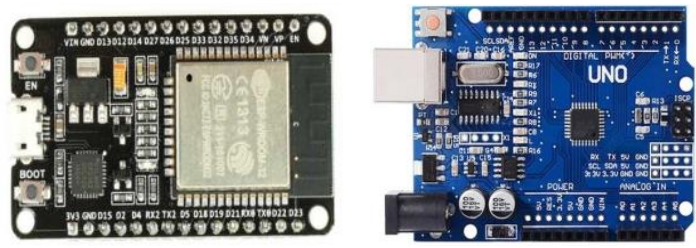

Figure 2. Arduino Uno and Module of ESP 32

\section{METHOD}

In general, the method used in this research consists of designing hardware and designing software in an automation system and monitoring the hydroponic cultivation process in improving the quality of the results of the internet-integrated plant.

\section{A. Hardware Design}

Hardware design consists of two main parts, namely the design of mechanical systems and the design of electrical systems. The design of a mechanical system consists of the physical form/ design of the system, while the electrical design consists of designing an electrical circuit system, sensors, and pump motors. Figure 3 shows the mechanical design of the system used and Figure 4 shows a block diagram for the overall hardware design.
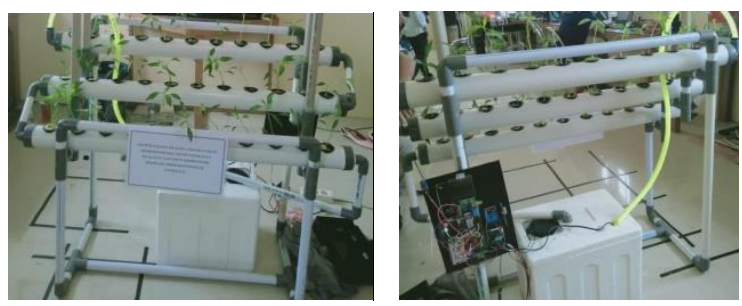

Figure 3. Design of System Mechanics

In the mechanical design above, paralon pipe materials of various sizes are used because these materials are strong and easily formed, coupled with other supporting materials such as bolts, plywood, etc.

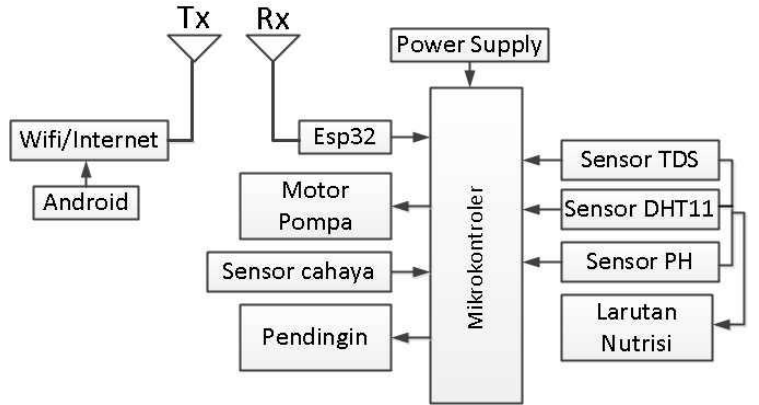

Figure 4. Overall Block Diagram (Hardware)

\section{B. Software Design}

Software design using C language programming, Arduino IDE as the main software for programming in the automation system and monitoring of the hydroponic cultivation process in improving the quality of the results of the internet-integrated plant and the software used to create android applications namely APP Inventor. Display of software can be seen in Figure 5. The whole software will adjust to the hardware that has been designed on the system.
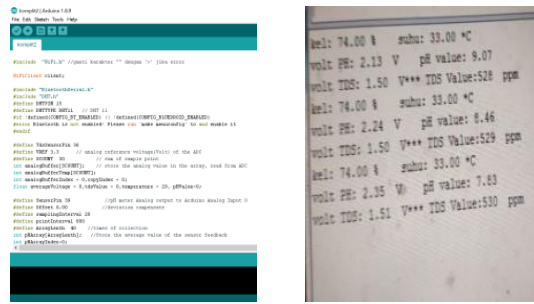

Figure 5. Display of Software Arduino IDE
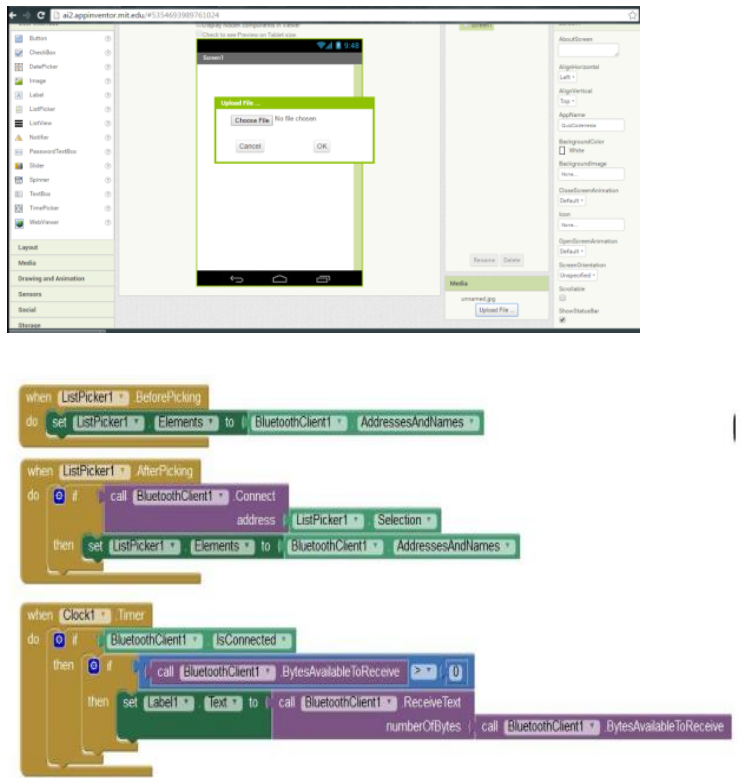

Figure 6. Display of Software APP Inventor 


\section{RESUlT}

The results discussed in this study include testing the monitoring system, reading all sensors in Android and web applications, testing the $\mathrm{PH}$ sensor, testing the TDS sensor, testing the light sensor on the water pump and testing the temperature sensor on the cooler.

\section{A. Testing the monitoring system on the reading of all sensors in the Android and web applications}

In this test, it can be seen from changes in sensor reading data displayed through the android application and web display "thingspeak.com". Display images of android and web applications can be seen in the image below:

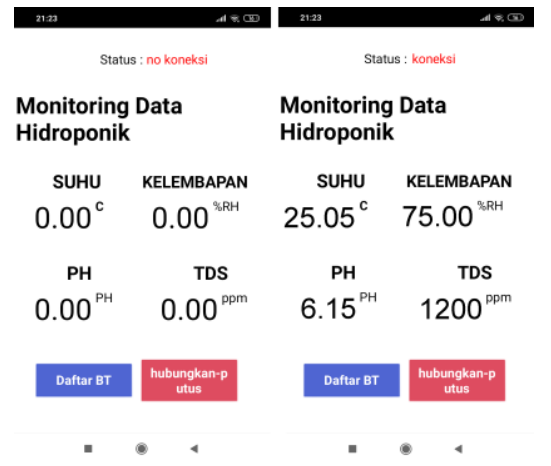

Figure 7: Application display of monitoring android

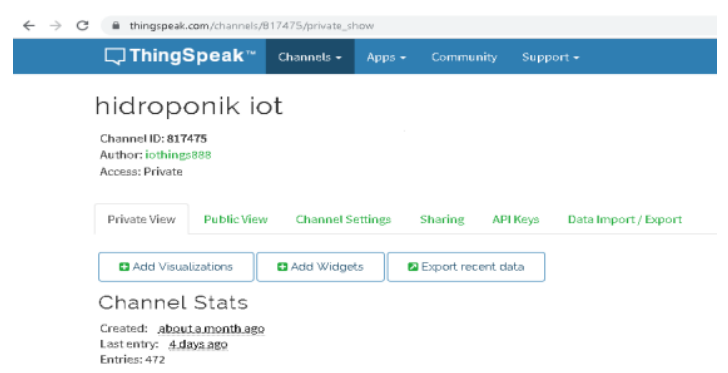

Figure 8: Display of monitoring applications via the Web

\section{B. Testing of PH Sensors}

This test shows that the $\mathrm{PH}$ sensor is used to detect the acidity level of nutrient solution in hydroponic plants. Data output from sensors in the form of analog data is then converted into digital data. To test the accuracy of the $\mathrm{PH}$ sensor will be compared with the original PH solution. For the results of a comparison between the $\mathrm{PH}$ sensor with the original $\mathrm{PH}$ solution can be seen in table 1 .
Table 1. Testing of PH Sensors

\begin{tabular}{|c|c|c|c|c|}
\hline \multirow{2}{*}{ No. } & \multicolumn{4}{|c|}{ Measurement } \\
\cline { 2 - 5 } & PH Sensor & $\begin{array}{c}\text { PH } \\
\text { solution }\end{array}$ & Deviation & Error (\%) \\
\hline 1 & 4,10 & 4 & 0,10 & 2,5 \\
\hline 2 & 6,05 & 6 & 0,05 & 0,83 \\
\hline 3 & 6,57 & 7 & 0,43 & 6,14 \\
\hline 4 & 10,11 & 10 & 0,11 & 1,1 \\
\hline
\end{tabular}

\section{Testing of TDS Sensor}

In this test, the TDS sensor is used to detect the concentration of nutrient solution in hydroponic plants. Data output from sensors in the form of analog data is then converted into digital data. To test the accuracy of the TDS sensor it will be compared to the TDS meter. For the results of comparison between PH sensors and TDS meters can be seen in table 2 .

Table 2. Testing of TDS Sensors

\begin{tabular}{|c|c|c|c|c|}
\hline \multirow{2}{*}{ No. } & \multicolumn{4}{|c|}{ Measurement } \\
\cline { 2 - 5 } & $\begin{array}{c}\text { Sensor of } \\
\text { TDS (ppm) }\end{array}$ & $\begin{array}{c}\text { TDS meter } \\
(\mathrm{ppm})\end{array}$ & Deviation & $\begin{array}{c}\text { Error } \\
(\%)\end{array}$ \\
\hline 1 & 517 & 500 & 17 & 3,4 \\
\hline 2 & 709 & 700 & 9 & 1,28 \\
\hline 3 & 1013 & 1000 & 13 & 1,3 \\
\hline 4 & 1120 & 1100 & 20 & 1,82 \\
\hline 5 & 1189 & 1200 & 11 & 0,92 \\
\hline
\end{tabular}

\section{Testing of light sensors on water pumps}

In this test, the light sensor (LDR) is used to detect the level of light intensity in hydroponic plant conditions. Data output from sensors in the form of analog data is then converted into digital data. To test the light sensor on the water pump can be seen in table 3.

Table 3. Testing of light sensors on water pumps

\begin{tabular}{|c|c|c|}
\hline \multirow{2}{*}{ No } & \multicolumn{2}{|c|}{ Measurement } \\
\cline { 2 - 3 }$\cdot$ & Light sensor & Condition of pump water \\
\hline 1 & Clear & ON \\
\hline 2 & Clear enough & ON \\
\hline 3 & Cloudy & OFF \\
\hline 4 & Dark & OFF \\
\hline
\end{tabular}

\section{E. Testing of temperature sensors on coolers}

In this test, the temperature sensor (DHT11) is used to detect the temperature of the hydroponic plant conditions. Data output from sensors in the form of analog data is then converted into digital data. To test the light sensor on the water pump can be seen in table 3. 
Table 4. Testing of temperature sensors on coolers

\begin{tabular}{|c|c|c|}
\hline \multirow{2}{*}{$\begin{array}{c}\text { No } \\
.\end{array}$} & \multicolumn{2}{|c|}{ Measurement } \\
\cline { 2 - 3 } & Temperature sensor $\left({ }^{\circ} \mathrm{C}\right)$ & Condition of Cooler \\
\hline 1 & 18 & OFF \\
\hline 2 & 20 & OFF \\
\hline 3 & 25 & OFF \\
\hline 4 & 27 & OFF \\
\hline 5 & 30 & ON \\
\hline 6 & 32 & ON \\
\hline
\end{tabular}

\section{Conclusion}

The testing results of the automation system and monitoring of the hydroponic cultivation process in improving the quality of the results of the internetintegrated plant conducted can prove that the system is capable and effective in doing its work well, namely the process of automation and monitoring of important variables in hydroponic cultivation, namely temperature, acidity (PH), and the thickness of the nutrient solution can work well. So that the problem of the incompatibility of nutrient solutions in hydroponic cultivation can be overcome. This shows that all the devices in this system have been successfully integrated and achieved the desired targets.

\section{REFERENCES}

Helmy. (2016). Nutrient Film Technique (NFT) Hydroponic Monitoring System. Journal of Applied Information and Communication Technologies, 1-6.

Garg, A. (2016). Application of Soil Moisture Sensor in Agriculture. Proceedings of Internation Conference on Hydraulic (pp. 8-10). India: Proceedings of Internation Conference on Hydraulic.

Prakosa, Y. (2019). Sistem Otomasi dan Monitoring Tanaman Hydroponic Berbasis real Time. Jurnal Pengembangan Teknologi Informasi dan Ilmu Komputer, 3285-3293.
M.F.Saaid. (2015). Automated PH Controller System for Hydroponic Cultivation. EEE Symposium on Computer Applications \& Industrial Electronics (ISCAIE). Malaysia: IEEE.

Kulkarni. (2017). Automation of Hidroponic System. International Journal of Science Technology \& Engineering.

Joshi, S. (2018). Automation in Hydroponic System using Control Circuit. International Journal Of Innovative Research in Science Engineering \& Technology.

Sahin. (2014). An expert System Design and Application for Hydroponic Greenhouse Systems. Gazi University Journal of Science.

Wiedjaja. (2017). Hydroponic System with Real Time OS Based On Arm Cortex-M Microcontroller. The International Conference on Eco Engineering development. Binus.

mouser.com. (2019). DHT11-Technical-Data-Sheet . Retrieved from www.mouser.com: www.mouser.com

sparkfun.com. (2019). PH Sensor datasheet. Retrieved from sparkfun.com: https://cdn.sparkfun.com

media.digikey.com. (2019). TDS Sensor Datasheet. Retrieved from media.digikey.com: media.digikey.com

sparkfun.com. (2019). Mikrokontroler AVR Atmega328 datasheet. Retrieved from sparkfun.com: www.sparkfun.com

sparkfun.com. (2019). ESP32 datasheet. Retrieved from sparkfun.com: cdn.sparkfun.com 